\title{
Ortopedi ve travmatoloji eğitimindeki bilimsel çalışmalar
}

\section{Scientific research in orthopedics and traumatology training}

\author{
Cem Albay', Ahmet Güray Batmaz² \\ ${ }^{1}$ Bağcılar Eğitim ve Araştırma Hastanesi, Ortopedi ve Travmatoloji Kliniği, İstanbul \\ ${ }^{2}$ Medipol Mega Hastanesi, Ortopedi ve Travmatoloji Kliniği, İstanbul
}

Günümüzde hayat standartlarının değişmesi, yaşam kalitesi kavramındaki değişiklikler, ortalama ömrün uzaması, hastaların ve doktorların tıbbi ve cerrahi tedaviden beklentilerinin artması, rekabetçi ortam, teknolojik yenilikler, bu yeniliklerin bilgiye ulaşmada yarattığı kolaylıklar; doktor ve cerrahları var olan tedavi rejimlerinde değişiklikler yaratmaya itmiş, tüm pozitif bilimlerde olduğu gibi ortopedi ve travmatolojide de yeni buluşlara, bunlar da ortopedi uygulamalarında değişikliklere neden olmuştur. Bütün bu buluşlar ve yenilikler bilimsel araştırmalar sonucunda olmuştur. Bilimsel araştırma klinik açıdan bilimi yönlendirecek bir soru belirlemekle başlar; bu soru eşliğinde çalışma popülasyonu belirlenir; çalışma sonucunu etkileyecek değerler ortaya konur. Bu araştırmalar, yöntemine, sürecine, gözlemlediği popülasyonun sayı ve niteliksel özelliklerine göre tasarlanıp sınıflandırılabilir. Klinik araştırmalar gözlemsel ve deneysel olarak ikiye ayrılırlar. Olgu sunumları, olgu serileri, kohort çalışmaları, vaka(olgu)-kontrol çalışmaları, metaanalizler, kesitsel araştırmalar, deneysel çalışmalar bunlara örnek olarak verilebilir. Cerrahi eğitim gibi araştırma eğitimi de zahmetli ve yorucudur. Araştırmacılar en az 1-2 yıllık bir araştırma eğitimi alırlar. Bu sürecin zahmetli ve uzun oluşu, yapılan kaliteli araştırma sayısına da etki etmektedir. Buna rağmen, bilimsel araştırmalar yeni bilgi ve buluşları ortaya çıkararak, bilim dalını geliştirip var olan tetkik ve tedavi yöntemlerini geliştiren ve değiştiren en önemli unsurdur. Ortopedi ve travmatoloji bilim dalının klinik uygulamaları bu sayede sürekli gelişmekte ve değişmekte olup, bu durum pratikte kendini olumlu yönde göstermektedir. Bu yüzden bilimsel çalışmaların iyi bilinmesi, doğru şekilde yapılması, yorumlanması ve uygulamaya sokulması önemlidir.

Anahtar sözcülkler: klinik araştırma; bilim; epidemiyolojik çalışma; analiz; istatistiksel bilgi; biyoistatistik; eğitim
The change in living standards, changes in the concept of quality of life, the lengthening of the average life, increase of expectations of patients and doctors from medical and surgical treatment, competitive environment, technological innovations making easier the access to information; all these have pushed the physicians and surgeons to adopt change in the treatment regimens. As in all the positive sciences; the new inventions occur in orthopedics and traumatology, which lead to changes in the orthopedic practice. All these inventions and innovations have been achieved as the result of scientific researches. Scientific research starts with a set of questions which can guide clinical sciences. The working population is determined in the presence of these questions, and the findings which can affect the study are detected. These studies can be designed and classified according to the method, the process, the number, and the qualitative characteristics of the population. Clinical studies are classified as observational and experimental studies. Case reports, case series, cohort studies, case-control studies, meta-analyses, cross-sectional studies, experimental studies are some examples. Research education, such as surgical training, is also demanding and tiring. The researchers are trained for a minimum of 1-2 years. This laborious and lengthy process has an impact on the number of qualified researches. In spite of this, scientific research is the most important factor revealing new information and discoveries that improve and develop the tests and treatment regimens. So, clinical applications of orthopedics and traumatology is constantly changing and developing in practice, and this situation presents itself in a positive direction. Therefore, it is important that the scientific studies are handled with good knowledge, properly managed, interpreted, and applied correctly.

Key words: clinical research; science; epidemiologic study; analysis; statistical data; biostatistics; education

- Illetişim adresi: Yrd. Doç. Dr. Gazi Huri, Hacettepe Üniversitesi Tıp Fakültesi, Ortopedi ve Travmatoloji Anabilim Dalı, Ankara Tel: 0312 - 3051207 e-posta: gazihuri@hacettepe.edu.tr

- Geliș tarihi: 24 Ekim 2014 Kabul tarihi: 24 Ekim 2014 
O rtopedi ve Travmatoloji bir bilim dalı olarak hastanelere en sık başvuru nedenleri arasında gelen kas iskelet sistemi hastalıkları ile ilgilenir. Bu sistemin yapısal bozuklukları, hastalarda fonksiyonel ve psikolojik bozukluklar yaratma nedenleri arasında başta gelmektedir.

Günümüzde hayat standartlarının değişmesi, yaşam kalitesi kavramındaki değişiklikler, ortalama ömrün uzaması, hastaların ve doktorların tıbbi ve cerrahi tedaviden beklentilerinin artması, rekabetçi ortam, teknolojik yenilikler, bu yeniliklerin bilgiye ulaşmada yarattığı kolaylıklar; doktor ve cerrahları var olan tedavi rejimlerinde değişiklikler yaratmaya itmiş, tüm pozitif bilimlerde olduğu gibi ortopedi ve travmatolojide de yeni buluşlara, bunlar da ortopedi uygulamalarında değişikliklere neden olmuştur. ${ }^{[1,2]}$

Bütün bu buluşlar ve yenilikler bilimsel araştırmalar sonucunda olmuştur. Öğrenme, araştırma veya gözlem yolu ile elde edilen gerçeğe bilgi denir. ${ }^{[3]}$ Bilim ise evrenin veya olayların bir bölümünü konu olarak seçen, deneye dayanan yöntemler araştıran ve gerçeklikten yararlanarak sonuç çıkarmaya çalışan düzenli bilgidir; ${ }^{[3]}$ genel geçerlilik ve kesinlik nitelikleri gösterir, yöntemli ve dizgeseldir. Bilim, belli bir konuyu bilme isteğinden yola çıkar; belli bir amaca yönelen bir bilgi edinme ve yöntemli araştırma sürecidir. Bilimsel araştırma ise dayanaklı bilgilerden hareket ederek yeni bir şey bulmaya yönelik uğraştır. ${ }^{[3]}$ Temelini, doğruluğu test edilmiş, düşünme prensipleri ile çelişkili olmayan sistemli ve organize edilmiş bilgilerden alır. ${ }^{[4]} \mathrm{Bu}$ yüzden bilimsel araştırma, sistematik veri toplama ve analiz etme sürecidir. Bu süreç genel olarak beş safhada tanımlanmaktadır (Tablo 1). ${ }^{[5-9]}$

Tablo 1. Bilimsel araştırmanın evreleri

1. Araştırma sorusunun seçimi

2. Uygun yöntemin belirlenip çalışma programının yapılması

3. Verilerin toplanması

4. Malzemelerin belirlenmesi, incelenmesi

5. Sonucun çıkarılması

Tıbbi bir bilimsel araştırmanın asıl amacı klinik olarak saptanmış bir sorun karşısında gerçeği saptamak ve gerçeğe yönlendirmektir. Bu ise deneysel olarak klinik veya temel bilim konularında yapılır. Çalışmalarda toplanan istatistiksel değerlerin doğru analizi ise çalışmaların sonucunu sunar.

Bilimsel araştırma klinik açıdan bilimi yönlendirecek bir soru belirlemekle başlar; bu soru eşliğinde çalışma popülasyonu belirlenir; çalışma sonucunu etkileyecek değerler ortaya konur. Bu araştırmalar, yöntemine, sürecine, gözlemlediği popülasyonun sayı ve niteliksel özelliklerine göre tasarlanabilir. ${ }^{[10]}$

\section{BILIMSEL ÇALIŞMALAR}

Klinik araştırmalar gözlemsel ve deneysel olarak ikiye ayrılırlar. Gözlemsel çalışmalarda ileriye dönük veriler toplanabilir veya geçmişe yönelik inceleme yapılabilir. ${ }^{[5,6]}$ Gözlemsel araştırmalar; vaka sunumları, vaka serileri, kesitsel çalışmalar gibi nedenselliği ortaya koyamayan, nispeten daha ucuz tanımlayıcı çalışmalar olabilmekle birlikte; farklı değişkenlerin birbiriyle ilişkisini ortaya koyan, planlama esasına dayanan vaka-kontrol çalışmaları, kohort çalışmaları, metaanalizler gibi analitik gözlemsel çalışmalar olabilir. Analitik gözlemsel çalışmalar, nedenselliğin belirlenmesinde, hastalık seyrinin incelenmesinde önemlidir. ${ }^{[9]}$

Gözlemsel araştırmalar geriye dönük (retrospektif), veya ileriye dönük (prospektif) olabilir. Retrospektif araştırmalar bir sonuca neden olabilecek durumları inceler. Vaka-kontrol çalışmaları buna örnek verilebilir. Prospektif çalışmalarda ise belirlenen bir etmenin beklenen sonuca etkisi incelenir. Bu etmenin beklenen sonuca olan etkisinin süresi veya sıklığı incelenebilir.

\section{Olgu sunumları}

Tek hastayı ilgilendiren bir patolojiyi veya tek hastaya uygulanan tedavi rejimini sunar; bu yüzden ayrıntıdan uzaktır ve tek vaka üzerinden genelleme yapılmasına izin vermez; nedensel değildir ve bilimsel değeri en az olan bir makale türüdür. Genellikle yeni veya çok nadir görülen bir hastalığı, yan etkiyi ya da komplikasyonu bildirdiğinden yine de önemlidir. ${ }^{7-9]}$

\section{Olgu serileri}

Belli bir ortak noktası olan hastaların sonuçlarını sunar. Bu tip çalışmalar, geriye dönük olarak tıbbi kayıtlar üzerinden bildirim yapan, ortak bir grubu ayrıntılandıran tanımlayıcı gözlemsel çalışmalardır.

\section{Kohort çalışmaları}

Benzer özellikleri veya benzer risk etmenlerine sahip hasta gruplarını ileriye veya geriye dönük inceler. Bir hastalığın sıklığı ve göreli riskinin belirlenmesinde kohort çalışması kullanılır.

İleriye dönük kohort çalışmalarında kohortun seçiminde, kohortun araştırılan hastalık açısından risk grubu olması önemlidir. Kohort seçiminde grup içerisinde etkene farklı miktarlarda maruz kalınmış olması da kullanılabilir veya kohort grupları subkohort gruplara bölünebilir. Kohort çalışmalarında hastaların izlemi, etkenlerin yakın takibi önemlidir. 
İleriye dönük kohort çalışmaları, etkenlerin ayrıntılı takibine izin vermesi, kayıt altına alınmasına olanak sağlaması nedeniyle en değerli gözlemsel çalışmalardır.

Geriye dönük kohort çalışmaları ise tutulan kayıtlar üzerinden yapılan çalışmalardır. Bu nedenle, tutulan kayıtların güvenilir ve eksiksiz olması önemlidir. Geriye dönük kohort çalışmalarında belirlenen bir hasta grubunun herhangi bir etkene olan maruziyeti ve olası sonucu, geçmiş dosyalara bakılarak incelenir. Ülkemiz şartlarında hastane kayıt sistemlerinin güvenilirliği sorgulanmalıdır.

\section{Vaka(olgu)-kontrol çalışmaları}

Herhangi bir hastalığı/yaralanma tipi olan olgular (vakalar) ve bu hastalığı/yaralanması olmayan bir kontrol grubu kullanır. Bu çalışma tipi, kohort çalışma grubundaki gibi herhangi bir etkene maruz kalınmaya bağlı oluşan olgu sayısı yerine, olgular ve kontrollerdeki etkene maruz kalma oranını kıyaslar. Yani bu çalışma tipi kohort çalışma tipinin tersini inceler. Vaka-kontrol çalışmaları, bir durumun olma olasılığının olmama olasılığına oranını verir ve bu orana odds oranı adı verilir. ${ }^{[11]}$ Göreceli olasılıklar oranı adıyla da kullanılır.

Vaka-kontrol çalışmaları, seyrek görülen olguların nedenlerini belirlemek açısından uygundur. Geriye dönük vaka-kontrol çalışmalarının olumsuz yanı, kayıtlara erişim zorluğu, kayıtların güvenilirlik ve eksiksizliğinin şüpheli oluşu ve yanlılıktır. Vaka-kontrol çalışmaları geriye dönük incelemelere dayandırılabileceği gibi ileriye dönük olarak da yapılabilir. Olgu ve kontrol gruplarının eş zamanlı oluşu, yanlılı̆̆ (bias) önlemeye yardımcı olur. ${ }^{[9,10]}$

\section{Kesitsel araştırmalar}

Belli bir zamanda, belli özelliklere sahip hasta popülasyonunu inceler. Bir toplumda bir sonuca etki eden etkenleri araştırır. Bu tip çalışmalar diğer çalışmalara kaynak oluşturacak veritabanları oluşturur; demografik özellikleri belirler ve bir hastalık hakkında prevalans sunar. Kesitsel çalışmalar hasta takibi yapmaz, anlık değerleri sunar. Bu yüzden kesitsel çalışmalar için bir kohortun resminin çekilmesi olarak nitelendirilebilir. Bu tip çalışmalar risk etmeni araştırmak için uygun değildir. ${ }^{[10]}$

Ortopedi ve travmatolojide tanımlayıcı ve kontrollü laboratuvar çalışmaları da temel bilim araştırmaları arasında yaygındır ve klinik araştırma özelliklerini içerir. Bu çalışmalarda yanlııı, karıştırıcı etmenler gibi araştırma tasarım problemleri, tedavi yöntemleri rastlantısal seçilerek ve çalışma gruplarına eşit dağıtılarak giderilebilir. Kesitsel araştırmalar, araştırmacının veya hasta grubunun hangi çalışma grubunda olduğunu bilmediği tek kör çalışmalar ile hem hasta grubunun hem de araştırmacının hangi çalışma grubunda olduğunu bilmediği çift kör çalışmalar araştırmalardaki bias (yanlılık) problemini çözmek konusunda yararlı tekniklerdir. ${ }^{[10]}$

Deneysel araştırma tasarımlarındaki klinik çalışmalar altın standart yöntemlerdir. Grupların rastlantısal belirlendiği randomize kontrollü çalışmalar, ortopedik araştırmalarda en yüksek kanıt seviyesindedir. ${ }^{[4,12]}$

Literatür taramaları ise derlemeler, uzman görüşleri ve metaanalizler gibi geniş bir spektrumu içerir. Bunlarda, tüm çalışmalar sistematik bir şekilde seçilip değerlendirilmeli ve buna göre yorumlanmalıdır. Aksi takdirde yazar literatürü kendi bilgisi ile yorumlamanın dışına çıkamaz. ${ }^{[5]}$ Sistematik değerlendirme, tüm literatürün taranması safhasında araştırmaya dahil edilme veya dışında bırakma ölçütlerinin seçildiği kanıta dayalı bir özettir. ${ }^{[6,13]}$ Metaanalizler sistematik derlemelerin ölçümsel değerlendirilmesidir; sadece bir literatür derlemesi olmayıp, sistematik bir literatür taraması ile elde edilen verilerin bir araya toplanıp, yeniden değerlendirilerek, belli bir etkenin, belirli bir sonuç üzerine olan etkilerini istatistiksel olarak daha anlamlı düzeyde ortaya koyma işlemidir; klinik kararlara destek olur ve uygulama kılavuzları oluşturur. ${ }^{[9,13]}$

Tıbbi çalışmaların kanıt seviyeleri, neden-sonuç ilişkisini en iyi açılayan çalışma Seviye I olacak şekilde sıralanır (Şekil 1). Buna göre;

Seviye I: İleriye dönük randomize kontrollü çalışma, randomize kontrollü çalışmanın metaanalizi veya sistematik derlemesi;

Seviye II: Randomize olmayan en az bir kontrollü çalışma, ileriye dönük kohort çalışma, deneysel çalışma;

Seviye III: Vaka-kontrol çalışmaları, vaka-kontrol çalışmalarının metaanalizi;

Seviye IV: Kontrolü olmayan olgu serileri;

Seviye V: Belli kritik değerlendirme, fizyolojik temel, referans araştırma olmadan, saygın uzman görüşü, komite raporları

olarak belirtilebilir. ${ }^{[4,14,15]}$

\section{TARTIŞMA}

Buna göre, 22. Ulusal Ortopedi Kongremize sunulan 860 bildiri incelendiğinde, ilk sırayı \%51 ile Seviye IV (kontrolü olmayan olgu serileri), ikinci sırayı ise \%26 ile olgu sunumları almıştı. Kanıt seviyesi I ve II olan araştırmaların oranı ise \%3'te kalmıştı. Sekiz yüz altmış bildiriden 77'si $(\% 8,95)$ deneysel araştırma idi. Bunların 49'u hayvan deneyi $(\% 63,6)$, 4'ü in vitro deney (\%6,3) idi. ${ }^{[16]}$ AAOS toplantısına 1996 yılında sunulan 465 bildirinin $\% 26,2$ 'sinin deneysel çalışma 


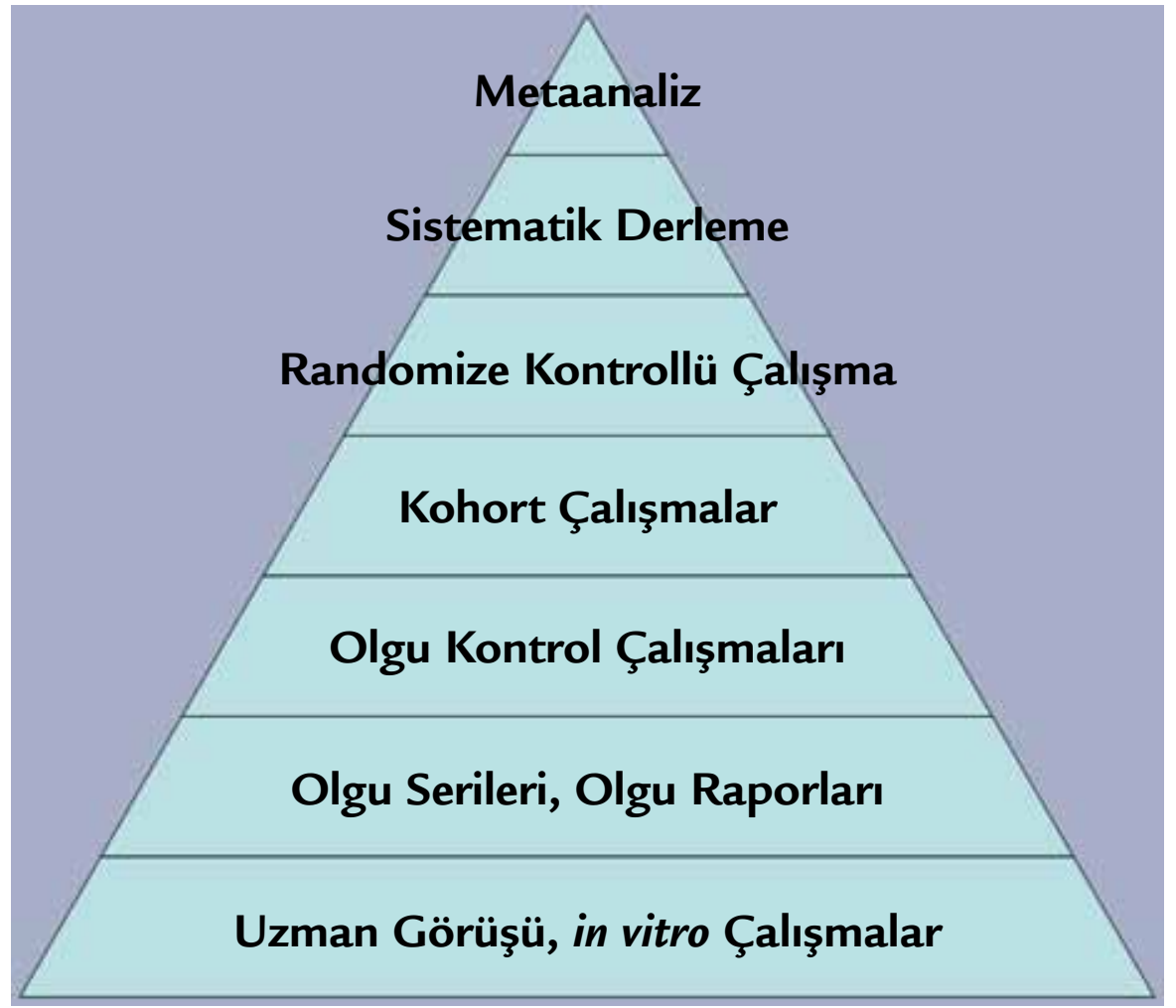

Şekil 1. Kanıta Dayalı Tıp Piramidi. ${ }^{[4,14,15]}$

olması ile kıyaslandığında bizim kongremizdeki \%8,95 değeri göze çarpmaktadır. ${ }^{[17]}$

\section{SONUÇ}

Cerrahi eğitim gibi araştırma eğitimi de zahmetli ve yorucudur. Araştırmacılar en az 1-2 yıllık bir araştırma eğitimi alırlar. Bu sürecin zahmetli, uzun oluşu yapılan kaliteli araştırma sayısına da etki etmektedir. ${ }^{[18]}$ Klinisyen araştırmacıların araştırmalarına ayırdıkları sürenin zamanlarının \%20'sini geçemediği belirtilmiştir. $^{[1,5]}$ Daha kaliteli, tıp dünyasını yönlendirici çalışmaların ortaya çıkmasını sağlayabilmek için araştırmacı grupları kurulmalı, sistematik araştırmacı eğitim programları oluşturulmalı, maaş destekleri, kaynak oluşturulması, alet-aygıt sağlanması gibi yöntemlerle araştırmacıların yeni buluşlar için desteklenmesi sağlanmalıdır. ${ }^{[1]}$

Bilimsel çalışmalar esnasında gerek asistan doktor gerekse üniversite öğrencisi seviyesinde gençlere de çalışmalara yardımcı olarak veya yürütücü olarak önemli görevler düşmektedir. Gençlerin yürütülen çalışmalara henüz öğrenci iken katılması, bilimsel çalışma kültürünün aşılanması, bunun için programlar yapılarak önlerinin açılması, yaptıkları çalışmalar ile onurlandırılarak yeni çalışmalara katılmalarına olanak sağlanması, üniversitelerde bilimsel çalışmalara özendirecek derneklerin kurulmasının önünün açılması, dernek vb. kuruluşlar ile maddi destekler sağlanarak planlama esnasında çalışmaların yapılabilirliğinin sağlanması, asistan-doktor eğitim sürecinde, eğitim planlamaları içerisine bilimsel çalışma yapmaya yönelik eğitimin de dahil edilmesi, eğitim ve çalışma programlarının bilimsel çalışma yapmaya olanak sağlayacak şekilde yapılması önemlidir.

Bu süreç içerisinde hem Sağlık Bakanlığına, hem hastane yönetimlerine, hem de üniversite yönetimine, ayrıca bilim dalını temsil eden kurum ve kuruluşlara büyük görevler düşmektedir.

Eğitim ve uygulama dönemleri uzun ve zahmetli olan cerrahi branşlarda bilimsel çalışmalar yapmak dahili branşlara göre ne kadar zor olsa da; ${ }^{[5]}$ bilimsel araştırmalar yeni bilgi ve buluşları ortaya çıkararak, bilim dalını geliştirip var olan tetkik ve tedavi yöntemlerini geliştiren ve değiştiren en önemli unsurdur. Ortopedi ve travmatoloji bilim dalının klinik uygulamaları bu sayede sürekli gelişmekte ve değişmekte olup, bu durum pratikte kendini olumlu yönde göstermektedir. Bu yüzden bilimsel çalışmaların iyi bilinmesi, doğru şekilde yapılması, yorumlanması ve uygulamaya sokulması önemlidir. 


\section{KAYNAKLAR}

1. Rosenberg L. Physician-scientists-endangered and essential. Science 1999;283(5400):331-2.

2. Brand RA, Hannafin JA. The environment of the successful clinician-scientist. Clin Orthop Relat Res 2006;449:67-71.

3. TDK. Türkçe Sözlük; 2014.

4. Elmalı N. Kanıta Dayalı Ortopedi Makalenin Bilimsel Değeri. http://totek.totbid.org.tr/files/TBAOMalatya/037.pdf

5. O'Keefe RJ, Huffman GR, Bukata SV; American Academy of Orthopaedic Surgeons. Orthopaedic Research: Clinical Epidemiology and Biostatistics. In: Orthopaedic Knowledge Update 9; 2008. p.173-85.

6. Hart JM. Research Design and Biostatistics, Chapter 13. In: Miller MD, Thompson SR, Hart JA, editors. Review of Orthopaedics, 6th ed. Philadelphia, PA: Elsevier-Saunders; 2012. p.829-40.

7. Dr. Gökhan Özsoy - Bilimsel Araştırma Yöntemleri.

8. Kara R. Bilimsel Araştırma Yöntemleri. http://www.nigde. edu.tr/ckfinder_portal/userfiles/files/BAY-1.pdf

9. Flynn JM; American Academy of Orthopaedic Surgeons. Orthopaedic Research: Health Research Methodology. In: Orthopaedic Knowledge Update 10; 2011. p.167-80.
10. Aşçıoğlu S. Hastane İnfeksiyonları Araştırmalarında Kullanılan Gözlemsel Çalışma Tasarımları. Hastane Infeksiyonları Dergisi 2006;10(4):205-10.

11. Grimes DA, Schulz KF. Making sense of odds and odds ratios. Obstet Gynecol 2008;111(2 Pt 1):423-6. CrossRef

12. Benson K, Hartz AJ. A comparison of observational studies and randomized, controlled trials. N Engl J Med 2000;342(25):1878-86.

13. Wright RW, Brand RA, Dunn W, Spindler KP. How to write a systematic review. Clinical Orthop Relat Res 2007;455:23-9.

14. Bernstein J. Evidence-based medicine. J Am Acad Orthop Surg 2004;12(2):80-8.

15. Oxford Centre for Evidence Based Medicine (CEBM): www. cebm.net

16. Öztuna V. Deneysel Çalışma Modelleri. TOTBID Temel Bilimler ve Araştırma Kış Okulu Kursu Ders Sunumları. http:// totek.totbid.org.tr/files/TBAOMalatya/036.pdf

17. Bhandari M, Devereaux PJ, Guyatt GH, Cook DJ, Swiontkowski MF, Sprague S, Schemitsch EH. An observational study of orthopaedic abstracts and subsequent full-text publications. J Bone Joint Surg Am 2002;84-A(4):615-21.

18. Bhandari $M$, Joensson A. Clinical Research for Surgeons. Stuttgart, Germany: Georg Thieme Verlag; 2009. 